\title{
Acute tumour bleeding in a patient with tuberous sclerosis and bilateral renal angiomyolipomata
}

\author{
Raymond WM Kan *, CF Kan, WH Au
}

Hong Kong Med J 2015;21:286.e1

DOI: $10.12809 / \mathrm{hkmj} 144320$

A 20-year-old woman presented to our hospital with tuberous sclerosis in January 2007. She had bilateral enlarging renal angiomyolipomata. She presented with a 1-day history of acute-onset severe right loin pain. She had no recent history of haematuria and her haemodynamics were stable. Figure a shows bilateral fat-containing renal masses, compatible with bilateral renal angiomyolipomata. The left kidney (black arrows) was displaced and compressed by a large renal angiomyolipoma in front of it. In the right kidney, there were multiple fat-containing renal angiomyolipomata. There was a rim of haematoma surrounding the right kidney (white arrows), indicating a recent haemorrhage. Figure b shows a crescent-shaped hyperdensity (white dotted arrows), indicating active tumour bleeding. On the left side, although there was no active bleeding, the thick- calibre artery supplying the renal angiomyolipoma (black dotted arrow) showed the vascular nature of this tumour. This patient was later successfully treated by transcatheter superselective arterial embolisation.

Brain magnetic resonance imaging of the same patient (Fig c) showed an enhancing subependymal nodule at the left lateral ventricle (white arrow). This lesion was suggestive of a giant cell astrocytoma, which is typically associated with tuberous sclerosis complex.

RWM Kan *, MB, BS, MRCSEd

CF Kan, MB, BS, FHKAM (Surgery)

WH Au, MB, BS, FHKAM (Surgery)

Department of Surgery, Queen Elizabeth Hospital, Jordan, Hong Kong

* Corresponding author: kwm.raymond@yahoo.com
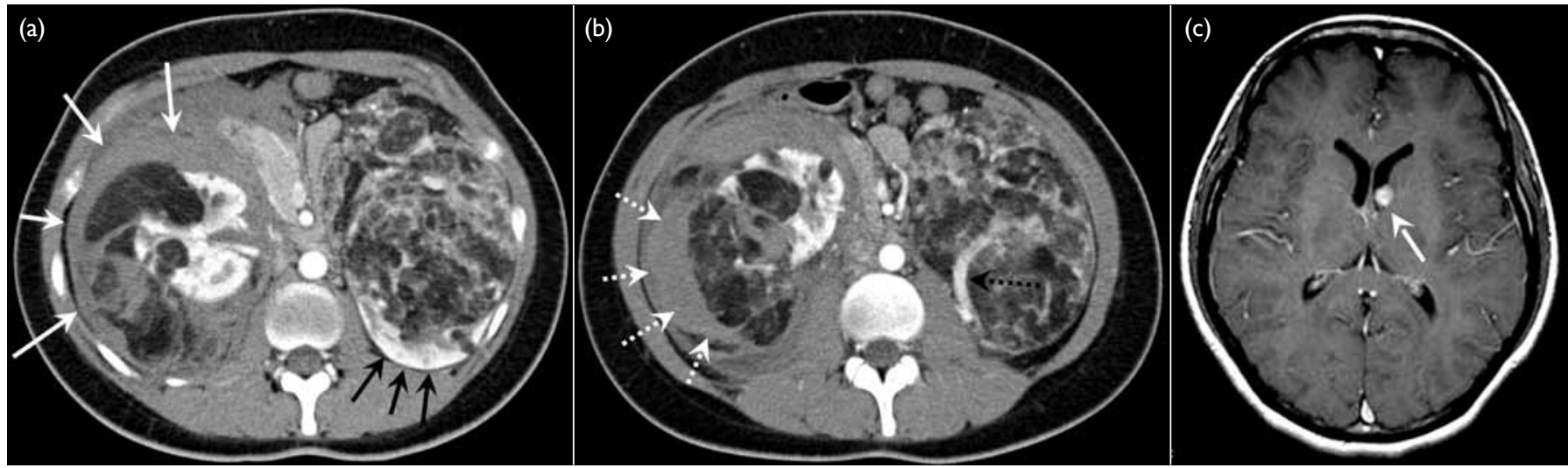